\title{
Design of Nano-Sized Pt Metals Synthesized on Ti-Containing Mesoporous Silicas and Efficient Catalytic Application for NO Reduction
}

\author{
Kohsuke Mori ${ }^{1}$, Sayoko Shironita ${ }^{1, *}$, Toshiaki Shimizu ${ }^{1, *}$, Takao Sakata $^{2}$, \\ Hirotaro Mori ${ }^{2}$, Tetsutaro Ohmichi ${ }^{1}$ and Hiromi Yamashita ${ }^{1}$ \\ ${ }^{1}$ Division of Materials and Manufacturing Science, Graduate School of Engineering, Osaka University, Suita 565-0871, Japan \\ ${ }^{2}$ Research Center for Ultra-High Voltage Electron Microscopy Osaka University, Ibaraki 567-0047, Japan
}

\begin{abstract}
A novel method to prepare the nano-sized Pt metal catalysts is proposed. Mesoporous silicas containing highly dispersed titanium oxide species (Ti-HMS) can act as the platform to generate highly dispersed Pt metal particles. Characterization by Pt $\mathrm{L}_{\mathrm{III}}$-egde XAFS, CO adsorption, and TEM analyses revealed that the size of formed Pt metal particles depends on the presence of titanium oxide species and that the smaller sizes of Pt metal particles was obtained with increasing the Ti contents in the silica matrix. These nano-sized Pt metal catalysts are useful as efficient catalysts for NO reduction, and higher conversion could be attained with smaller size of Pt metal particles. The present technique using Ticontaining mesoporous silicas as catalyst supports make a great contribution to minimize the amount of precious metals in order to meet today's industrial requirements. [doi:10.2320/matertrans.ML200702]
\end{abstract}

(Received August 1, 2007; Accepted December 3, 2007; Published February 25, 2008)

Keywords: nano-sized metal catalyst, platinum, mesoporous silica, tetrahedral titanium oxide

\section{Introduction}

Platinum is one of the most precious catalyst metals, but frequently employed in a wide variety of industrial catalytic process, especially for the removal of nitrogen oxides $\left(\mathrm{NO}_{x}\right)$ from the automobiles. ${ }^{1)}$ The potential catalyst that can efficiently remove $\mathrm{NO}_{x}$ emissions is particularly desired to meet upcoming diesel emission standard. ${ }^{2)} \mathrm{NO}_{x}$ have been causing severe environmental and health damages. Less than $2.0 \mathrm{~g} / \mathrm{kWh}$ for $\mathrm{NO}_{x}$ are now prescribed in Japan. Other examples of Pt metal catalysts are chemical processing of bulk and specialty chemicals, clean hydrogen production for the emerging hydrogen economy, including fuel cells, and sensors to detect poisonous or flammable gases or substances in solution. ${ }^{3)}$ These versatile applicability of $\mathrm{Pt}$ metal catalysts is making progress toward manufacturing highly active catalysts with reliable durability in order to minimize the quantity consumed.

The unique and fascinating properties of mesoporous molecular sieve materials have opened new possibilities for many application areas not only in catalysis but also for support materials, which possess large surface area as well as ordered hexagonal mesopore channels ranging from 1.5$10 \mathrm{~nm} .^{4,5)}$ These materials have been doped with transition metals in the frameworks with the intention of developing materials that exhibit unique properties. The transition metal oxide moieties are considered to be highly dispersed and also to be well-defined catalysts, which exist in the specific structure of the framework. These transition metal oxide moieties such as tetrahedrally coordinated titanium oxide moieties incorporated and isolated within silica matrixes have been named as "single-site catalysts". ${ }^{6-13)}$ Although the previous studies for the utilization of Ti-containing mesoporous silica have mainly been focused on their catalytic activity, the application to synthesize nano-sized metal catalysts has not been investigated so far.

In the present study, nano-sized metal catalysts have been

${ }^{*}$ Graduate Student, Osaka University deposited on the Ti-containing hexagonal mesoporous silica (Ti-HMS) with different Ti/Si ratios. We have successfully utilized the highly dispersed titanium oxide moieties included within mesoporous silica (Ti-HMS) as anchors to disperse metal particles highly. The interesting aspects such as characterization of nano-sized Pt metal catalysts as well as their prominent catalytic performances for NO reduction were also investigated.

\section{Experimental Section}

The synthesis of the Ti-containing mesoporous silica (TiHMS) was carried out using tetraethyl orthosilicate (TEOS: $\left.\mathrm{Si}(\mathrm{OEt})_{4}\right)$ as a silica source, tetrapropyl orthotitanate (TPOT: $\left.\mathrm{Ti}\left(\mathrm{O}^{i} \mathrm{Pr}\right)_{4}\right)$ as a titanium source, and dodecylamine as a template. ${ }^{12)}$ The $\mathrm{Ti} / \mathrm{Si}$ ratios were 0.01 , and 0.1 . The products were named as Ti-HMS (0.01) and Ti-HMS (0.1), respectively. The HMS was also prepared by the same method without TPOT. The Pt loading on HMS and Ti-HMS with different $\mathrm{Ti} / \mathrm{Si}$ ratios were performed by impregnation method from an aqueous solution of $\mathrm{H}_{2} \mathrm{PtCl}_{6}$, followed by drying at $383 \mathrm{~K}$ and reduction by $\mathrm{H}_{2}\left(20 \mathrm{~mL} \mathrm{~min}^{-1}\right)$ at $473 \mathrm{~K}$ for $1 \mathrm{~h}$. The obtained products were named as $\mathrm{Pt} / \mathrm{HMS}, \mathrm{Pt} /$ Ti-HMS (0.01), and Pt/Ti-HMS (0.1), respectively (Pt: 1.0 mass $\%$ ).

The diffuse reflectance absorption spectra were recorded with a Shimadzu UV-2550 spectrometer at $295 \mathrm{~K}$. The XRD patterns were recorded with a Rigaku Mini-flex using $\mathrm{Cu} \mathrm{K} \alpha$ radiation of $\lambda=0.15418 \mathrm{~nm}$. The nitrogen adsorptiondesorption isotherms were carried out at $77 \mathrm{~K}$. By using an ASAP 2000 system (Shimadzu), the BET and BJH methods were applied for the determination of the specific surface area, and the mean mesopore diameter, respectively. The Ti K-edge and $\mathrm{Pt}_{\mathrm{III}}$-edge XAFS spectra were recorded at room temperature in the fluorescence mode at the BL-7C facilities of the Photon Factory at the National Laboratory for HighEnergy Physics, Tsukuba. TEM micrograph was recorded with Hitachi H-9500 operated at $300 \mathrm{kV}$.

The catalytic activity was investigated in NO reduction 


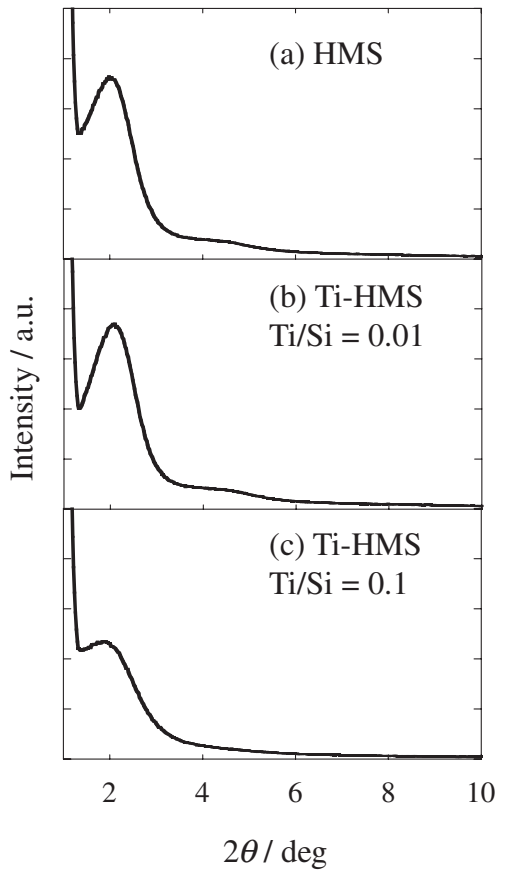

Fig. 1 XRD patterns of (a) HMS (b) Ti-HMS (0.01), and (c) Ti-HMS (0.1).

Table 1 XRD and $\mathrm{N}_{2}$ adsorption-desorption results of HMS and Ti-HMS with various $\mathrm{Ti} / \mathrm{Si}$ ratios.

\begin{tabular}{cccc}
\hline Sample & $\begin{array}{c}d_{100}{ }^{a} \\
/ \mathrm{nm}\end{array}$ & $\begin{array}{c}S_{\mathrm{BET}}{ }^{b} \\
/ \mathrm{m}^{2} \cdot \mathrm{g}^{-1}\end{array}$ & $\begin{array}{c}D_{\mathrm{BJH}^{c}} \\
/ \mathrm{nm}\end{array}$ \\
\hline HMS & 4.2 & 876 & 5.7 \\
Ti-HMS (0.01) & 4.4 & 921 & 5.2 \\
Ti-HMS (0.1) & 4.7 & 896 & 4.6 \\
\hline
\end{tabular}

${ }^{a} d$-value of (100) reflection.

${ }^{b}$ BET surface area

${ }^{c} \mathrm{BJH}$ adsorption average pore diameter

using a fixed-bet reactor enclosed in a quartz-tube placed in an electronic furnace. The catalyst $(0.1 \mathrm{~g})$ was placed in a quartz-tube reactor and heated at desired temperature in a gaseous mixture of $\mathrm{NO}(400 \mathrm{ppm}), \mathrm{O}_{2} \quad(5 \%)$, and $\mathrm{He}$ (balance) (total flow rate: $100 \mathrm{ml} / \mathrm{min}$ ). The $\mathrm{NO}$ conversion was continuously monitored by a $\mathrm{NO}_{x}$ meter.

\section{Results and Discussion}

As shown in Fig. 1, the XRD patterns of the HMS and TiHMS exhibited a diffraction peak at around $2-3^{\circ}$ associated with the $d_{100}$ spacing, indicating the presence of mesoporous structure. Ti-HMS showed no peaks corresponding to the crystalline $\mathrm{TiO}_{2}$ phase at the higher angle, revealing that titanium oxide moieties are highly dispersed in the mesoporous structure. The specific surface areas and average pore dimaters of HMS and Ti-HMS with diffrent $\mathrm{Ti} / \mathrm{Si}$ ratios measured by $\mathrm{N}_{2}$ adsorption are sammarized in Table 1 . The pore size distribution of the Ti-HMS increses with increasing the Ti content within the silica matrix. The coordination geometry of titanium oxide moieties in the present TiHMS $(0.01)$ and Ti-HMS(0.1) have been confirmed by diffuse reflectance UV-vis (DRUV-vis) absorption and Ti K-edge XAFS measurements. In their DRUV-vis spectra, the

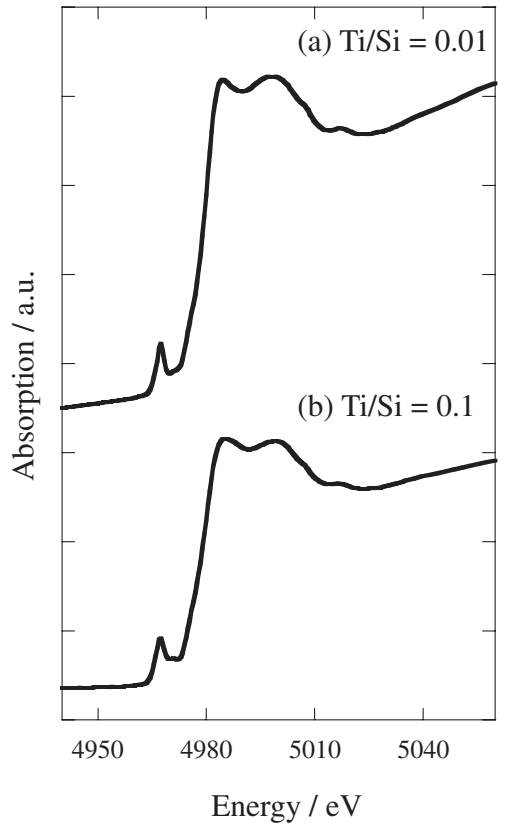

Fig. 2 Ti K-edge XANES spectra of Ti-HMS.

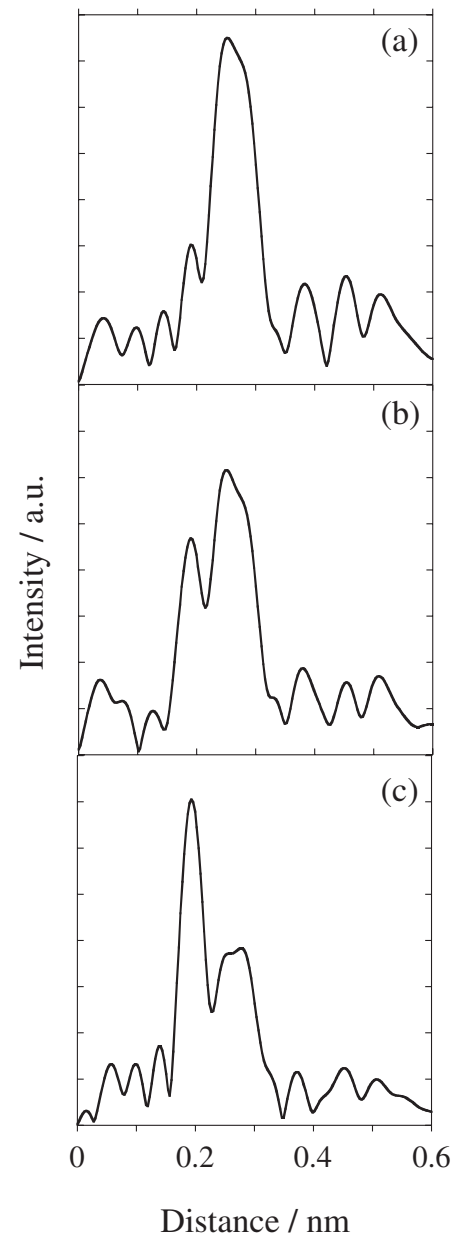

Fig. 3 Fourier transform of $\mathrm{Pt}_{\mathrm{III}}$-edge EXAFS of (a) Pt/HMS, (b) Pt/TiHMS (0.01), and (c) Pt/Ti-HMS (0.1).

Ti-HMS showed ligand-to metal charge-transfer band (LMCT) from $\mathrm{O}^{2-}$ to $\mathrm{Ti}^{4+}$ at around $215 \mathrm{~nm}$, and did not exhibit at wavelength regions longer than $340 \mathrm{~nm}$ detectable 
Table 2 The data obtained from the pulsed $\mathrm{CO}$ adsorption.

\begin{tabular}{cccc}
\hline Sample & $\begin{array}{c}\text { Dispersion } \\
/(\%)\end{array}$ & $\begin{array}{c}\text { Metal surface area } \\
/\left(\mathrm{m}^{2} \cdot \mathrm{g}^{-1}\right)\end{array}$ & $\begin{array}{c}\text { Average } \\
\text { particle size } \\
/(\mathrm{nm})\end{array}$ \\
\hline Pt/HMS & 3.4 & 8.6 & 32.7 \\
Pt/Ti-HMS $(0.01)$ & 3.7 & 9.1 & 30.7 \\
Pt/Ti-HMS(0.1) & 5.9 & 14.5 & 19.3 \\
\hline
\end{tabular}

for crystalline $\mathrm{TiO}_{2}$ powder. In the XANES spectra, Ti-HMS exhibit a single preedge peak at $4968 \mathrm{eV}$ corresponding to a dipolar-allowed transition from the $1 \mathrm{~s}$ to $\mathrm{t} 2$ molecular levels built from the $3 \mathrm{~d}$ and $4 \mathrm{p}$ metal orbital and from a neighboring orbital, as shown in Fig. 2. The observation of this intense preedge peak indicates that the titanium oxide moieties are highly dispersed in a mainly tetrahedral coordination.

The Pt/HMS and Pt/Ti-HMS were prepared by impregnating HMS and Ti-HMS powder $(\mathrm{Ti} / \mathrm{Si}=0.01$, and 0.1$)$ in the aqueous solution of $\mathrm{H}_{2} \mathrm{PtCl}_{6}$. The water was removed by evaporation, followed by drying at $383 \mathrm{~K}$ for $24 \mathrm{~h}$ and reduction by $\mathrm{H}_{2}$ at $473 \mathrm{~K}$ for $1 \mathrm{~h}$, giving Pt/HMS, Pt/Ti-HMS (0.01), and Pt/Ti-HMS (0.1), respectively (Pt: 1.0 mass\%).

The Fourier transforms of $\mathrm{Pt} \mathrm{L}_{\mathrm{III}}$-edge EXAFS spectra of the Pt/HMS and Pt/Ti-HMS are shown in Fig. 3. The peaks at around 0.19 and $0.27 \mathrm{~nm}$ are assigned to the $\mathrm{Pt}-\mathrm{O}$ and $\mathrm{Pt}-$ Pt bonds, respectively. The presence of both peaks indicates the formation of nano-sized Pt metal. The intensity of the Pt$\mathrm{Pt}$ peaks are smaller than that of $\mathrm{Pt}$ metal powder, and decrease in the order of Pt/HMS $>\mathrm{Pt} / \mathrm{Ti}-\mathrm{HMS}(0.01)>\mathrm{Pt} /$ Ti-HMS (0.1), suggesting that the size of Pt metal particles depend on the Ti contents.

Table 2 shows the dispersion, surface area, and average particle size of Pt metals which can be estimated from the results of pulsed $\mathrm{CO}$ adsorption measurement, which well support the results obtained from XAFS measurement. The dispersion and surface area of Pt metal on the Ti-HMS increased with increasing $\mathrm{Ti}$ contents in the silica frameworks. The average particle size of Pt metals on Ti-HMS (0.1) is $19.3 \mathrm{~nm}$, which is much smaller than those on HMS and Ti-HMS (0.01), respectively. These results clearly
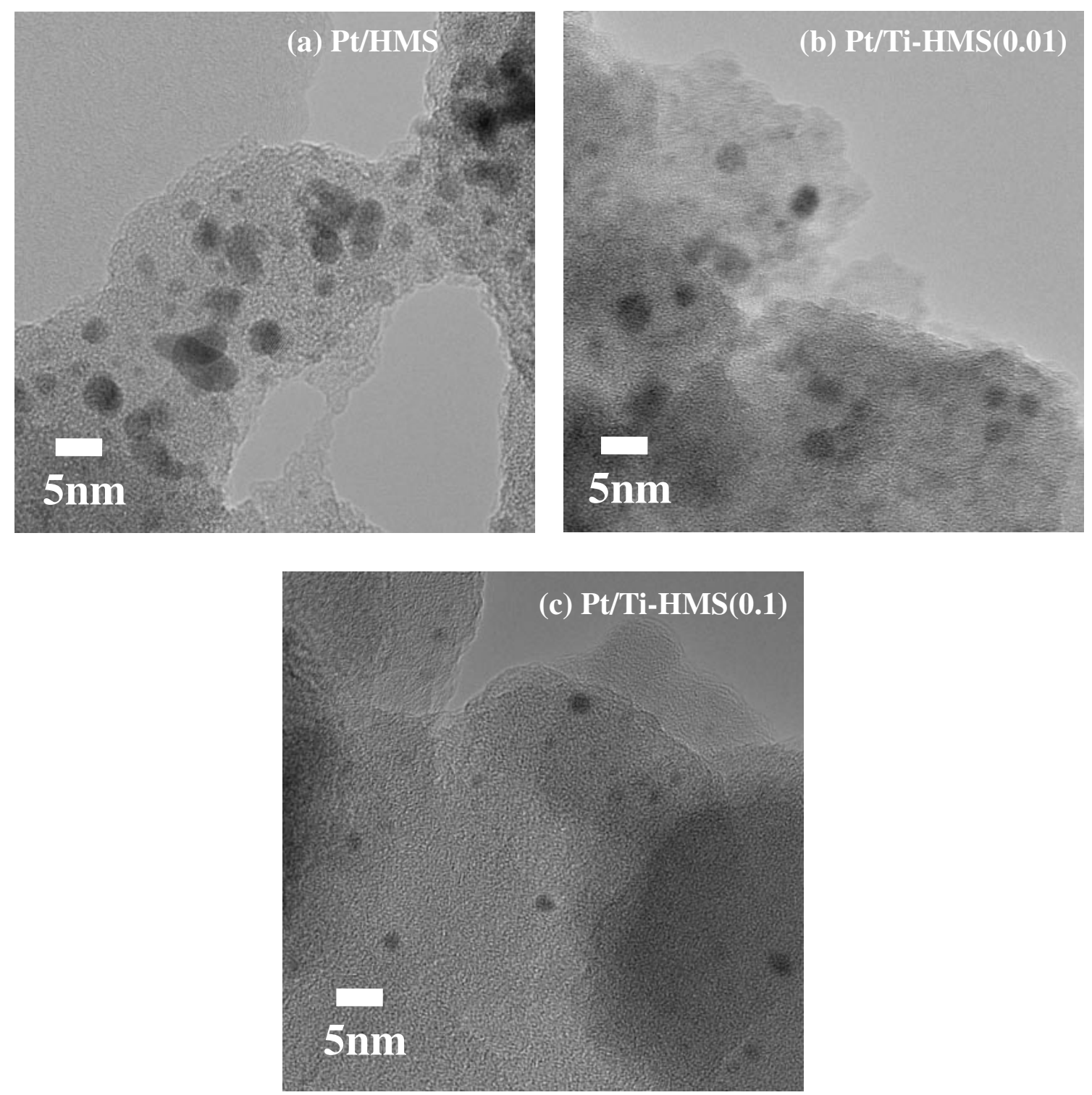

Fig. 4 TEM image of (a) Pt/HMS, (b) Pt/Ti-HMS(0.01), and (c) Pt/Ti-HMS(0.1). 


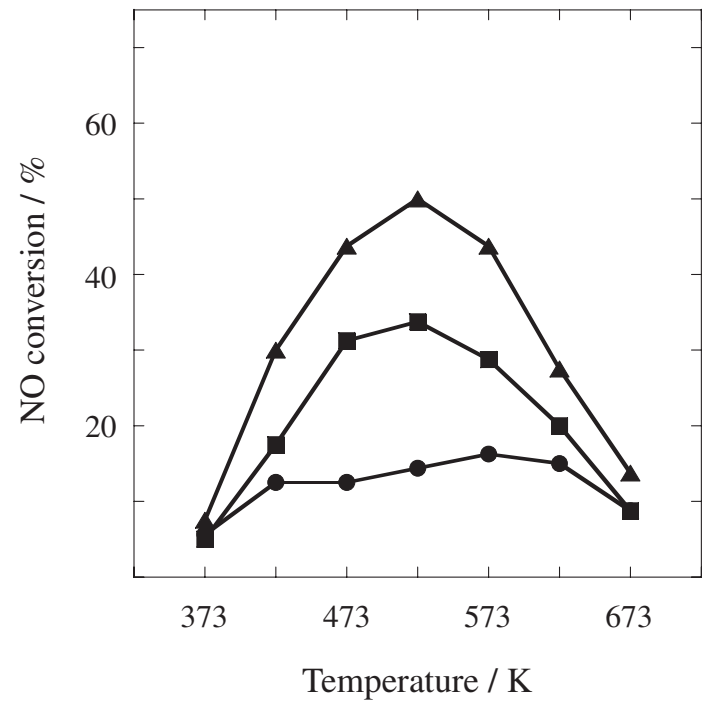

Fig. 5 Dependence of temperature for NO conversion with Pt/HMS $\mathrm{Pt} / \mathrm{Ti}-\mathrm{HMS}(0.01)(\boldsymbol{\square})$, and Pt/Ti-HMS(0.1) ( $\mathbf{\Delta})$.

suggest that the size of Pt metal particles depends on the presence of $\mathrm{Ti}$ atom and that the smaller sizes of Pt metal particles were obtained with increasing the Ti contents in the silica matrix.

The TEM images show that the Pt/Ti-HMS (0.1) has nanosized $\mathrm{Pt}$ metal with well-controlled size, as shown in Fig. 4(c), while the Pt/HMS and Pt/Ti-HMS (0.01) have Pt metal particles with various sizes (Figure 4(a) and 4(b)). These results are consistent with those of XAFS measurements. Although the sizes of Pt particles in TEM images are different from those obtained by $\mathrm{CO}$ adsorption, the importance of the Ti content was apparently demonstrated. The good correlation between Ti content and the size of $\mathrm{Pt}$ metal particles clearly indicates that the highly dispersed titanium oxide species act as anchors to disperse metal particles highly. Conclusively, varying the Ti content on TiHMS was demonstrated to be a convenient approach to control the size of Pt metal particles.

In order to evaluate the potential abilities of these $\mathrm{Pt}$ catalysts, the conversion of $\mathrm{NO}$ gas into $\mathrm{N}_{2}$ and $\mathrm{O}_{2}$ was carried out as a model reaction. The nano-sized Pt metal catalysts can be applied to the NO reduction with high efficiency. The results are shown in Figure 5. The size effect of the Pt metal particles on catalytic NO reduction was clearly observed: the highest conversion could be attained with Pt/Ti-HMS (0.1), while the Pt/HMS and Pt/Ti-HMS (0.01) with larger Pt metal particles showed substantially lower catalytic activity. Probably the high dispersion of $\mathrm{Pt}$ metal particle in the Pt/Ti-HMS (0.1) is preferable for the reduction of NO because of its high metal suface area. The reaction temperature also influenced on the reaction rates.
For all samples, the reduction of NO have an optimal reaction temperature. One possible explanation for the extensive lowering of catalytic activity at higher reaction temperature is the irreversible agglomeration of Pt metal, because color change of the catalyst from pale gray to deep gray.

\section{Conclusion}

Mesoporous silica materials comprising from highly dispersed titanium oxide moieties enables high dispersion of metal particles with the intention of developing prominent catalyst that exhibit the requisite activity for NO reduction. The interaction between the Pt precusor species and the titanium oxide moieties plays a crucial role for the generation of active nano-sized metal catalysts. The present simple methodology using Ti-containing mesoporous silica as a promising catalyst support can be applied to other catalyst metals, such as $\mathrm{Pd}, \mathrm{Au}, \mathrm{Rh}$, and has possibility to reduce the precious metals in industrial utilizations.

\section{Acknowledgment}

The present work is supported by the Grant-in-Aid for Scientific Research (KAKENHI) in Priority Area "Molecular Nan Dynamics" from Ministry of Education, Culture, Sports, Science and Technology (No. 17360388), (No. 1734036) $\&$ (No. 18656238). The X-ray adsorption experiments were performed at the Photon Factory of KEK (2005G039). This work is partly performed under the project of collaborative research at the Joining and Welding Research Institute (JWRI) of Osaka University.

\section{REFERENCES}

1) F. Klingstedt, K. Arve, K. Eränen and D. Y. Murzin: Acc. Chem. Res. 39 (2006) 273.

2) S.-S. Hong and G.-D. Lee: Catal. Today 63 (2000) 397.

3) F. Sen and G. Gokagac: J. Phys. Chem. C. 111 (2007) 1467.

4) C. T. Kresge, M. E. Leonowicz, W. J. Roth, J. C. Vartuli and J. S. Beck: Nature 359 (1992) 710.

5) Y. Tao, H. Kanoh, L. Abrams and K. Kaneko: Chem. Rev. 106 (2006) 896.

6) H. Yamashita and K. Mori: Chem. Lett. 36 (2007) 348.

7) H. Yamashita and M. Anpo: Current Opinion in Solid State \& Materials Science 7 (2004) 471.

8) H. Yamashita, S. Nishio, I. Katayama, N. Nishiyama and H. Fujii: Catal Today 111 (2006) 254.

9) K. Mori, S. Imaoka, S. Nishio, Y. Nishiyama, N. Nishiyama and H. Yamashita: Micropor. Mosopor. Mater. 101 (2007) 288.

10) M. Anpo and J. M. Thomas: Chem. Commun. (2006) 3273.

11) K. Ikeue, H. Yamashita, T. Takewaki and M. Anpo: J. Phys. Chem. B 105 (2001) 8350.

12) H. Yamashita, K. Ikeue, T. Takewaki and M. Anpo: Topics in Catal. 18 (2002) 95.

13) H. Yamashita, Y. Ichihashi, M. Anpo, M. Hashimoto, C. Louis and M. Che: J. Phys. Chem. 100 (1996) 16041. 